\title{
The effect of material interfaces on electrical tree growth and breakdown time of epoxy resin
}

DOI:

10.1109/CEIDP.2014.6995893

Link to publication record in Manchester Research Explorer

\section{Citation for published version (APA):}

Pattouras, M., \& Rowland, S. M. (2014). The effect of material interfaces on electrical tree growth and breakdown time of epoxy resin. In 2014 IEEE Conference on Electrical Insulation and Dielectric Phenomena (CEIDP) (pp. 365-368). IEEE. https://doi.org/10.1109/CEIDP.2014.6995893

\section{Published in:}

2014 IEEE Conference on Electrical Insulation and Dielectric Phenomena (CEIDP)

\section{Citing this paper}

Please note that where the full-text provided on Manchester Research Explorer is the Author Accepted Manuscript or Proof version this may differ from the final Published version. If citing, it is advised that you check and use the publisher's definitive version.

\section{General rights}

Copyright and moral rights for the publications made accessible in the Research Explorer are retained by the authors and/or other copyright owners and it is a condition of accessing publications that users recognise and abide by the legal requirements associated with these rights.

\section{Takedown policy}

If you believe that this document breaches copyright please refer to the University of Manchester's Takedown Procedures [http://man.ac.uk/04Y6Bo] or contact uml.scholarlycommunications@manchester.ac.uk providing relevant details, so we can investigate your claim.

\section{OPEN ACCESS}


This is the accepted manuscript, which has been accepted by IEEE for publication (C) 2014 IEEE. Personal use of this material is permitted. Permission from IEEE must be obtained for all other uses, in any current or future media, including reprinting/republishing this material for advertising or promotional purposes, creating new collective works, for resale or redistribution to servers or lists, or reuse of any copyrighted component of this work in other works. The full reference is:

\title{
'The effect of material interfaces on electrical tree growth and breakdown time of epoxy resin'
}

\author{
M. Pattouras, S. M. Rowland
}

IEEE Conference on Electrical Insulation and Dielectric Phenomena, Des

Moines, pp. 365-368 (2014)

DOI: $\underline{10.1109 / C E I D P .2014 .6995893}$ 


\title{
The effect of interface modification on electrical tree growth and breakdown of epoxy resin
}

\author{
M. Pattouras, S. M. Rowland* \\ The University of Manchester, School of Electrical and Electronic Engineering \\ Manchester, M13 9PL, United Kingdom \\ *E-mail: s.rowland@manchester.ac.uk
}

\begin{abstract}
This study investigates the effect of an interface on the lifetime of epoxy resin samples and the growth characteristics of electrical trees. Six sample types are presented; all having been prepared in the point-plane configuration using a needle -with a tip radius of $3 \mu \mathrm{m}$ - as the $\mathrm{HV}$ electrode. Most were molded in two parts producing an interface perpendicular to the field direction at the centre of the sample. Tests were carried out at $13 \mathrm{kV} \mathrm{rms}$ until sample breakdown occurred and sample images were taken at fixed one minute intervals during the test period. Results show that the interface modification affects electrical tree characteristics and improves the time to breakdown of the epoxy resin tested.
\end{abstract}

\section{INTRODUCTION}

Dielectric reliability is an increasingly important issue given the ageing plant in global power networks, and the move towards higher energy density urban systems. As such, the means to minimize the failures and extend the lifetime of dielectric materials used in HV equipment are continuously being investigated. Even though failure can in principle occur anywhere in a dielectric due to manufacturing imperfections such as voids, contaminants or even cracks, most faults in real power systems occur at joints or material interfaces. An example of this is that cable systems usual fail at joints or bushings[1]. Understanding the role of interfaces on failure processes is thus essential towards improving asset design and management.

In results shown in previous publications[1]-[3], the positive impact of interfaces perpendicular to the electric field is evident: increasing the samples' time to breakdown as well as increasing electrical tree inception time. Further investigation has been focused on modifying the interface and how this might be used to control the electrical tree growth as well as the samples' time to breakdown. This has been carried out by altering the interface's surface roughness using grit-blasting.

Long-term electrical breakdown testing is reported. Details of new sample fabrication techniques are described which enable better control of the material and interfaces, and data on tree length growth characteristics are discussed as well.

\section{EXPERIMENTAL}

\section{Materials used}

Samples were fabricated from Araldite LY5052 epoxy resin and amine hardener Aradur HY5052. Steel Ogura ${ }^{\mathrm{TM}}$ needles with a tip radius of $3 \mathrm{um}$ and diameter of $1 \mathrm{~mm}$ were used as the HV electrode. This needle was chosen in favor of the hypodermic needle used in the previous results presented (CEIDP'13)[1] since it is a needle widely used in the literature [4]-[6] and it also eliminates the silicon coating removal procedures needed to be followed with the previous electrode [7] thus minimizing the effect of any silicon residue on the results.

To enable construction of samples including interfaces perpendicular to the field, epoxy tablets were fabricated by pouring epoxy resin in $50 \mathrm{~mm}$ long $16 \mathrm{~mm}$ diameter cylindrical PTFE moulds. The material was cured for 24 hours at room temperature and then for 4 hours at $100^{\circ} \mathrm{C}$. The following day the epoxy was removed from the PTFE moulds and cut into $1 \mathrm{~mm}$ thick tablets using lathe equipment with a special cutting tool to minimize material loss and improve precision.

Final stages of molding took place in $25 \mathrm{~mm}$ square acrylic cubes, the bases of which were covered with PTFE to prevent bonding between the epoxy resin casted and molding platform. After the $1 \mathrm{~mm}$ thick epoxy tablets were modified, characterized and cleaned (described next), they were fixed firmly in the acrylic cube and they remained in their position as the liquid epoxy - which was mixed for 5 minutes and degassed - was poured into the molds. The needle electrode was placed $2 \mathrm{~mm}$ from the plane for all sample types fabricated (Figure 1). Six samples were fabricated for each sample type. If no interface was required, no tablet was included in the process.

The bottom side of the sample to be tested was painted with carbon black paint to ensure that a good contact between the sample's bottom and the ground plate. $13 \mathrm{kV}$ rms was applied to the needle from start to failure.

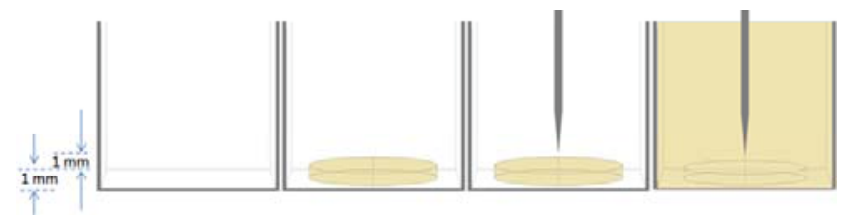

Figure 1. Stages of fabricating a sample with an interface perpendicular to the field.

\section{Interface modification}

The interfaces were modified by grit-blasting the epoxy tablet surface. This is a method involving the high pressure blasting of different grit types and sizes usually used to remove paint, rust or other surface coatings from wood and metals. For this particular case, glass beads (soft) and fused alumina (abrasive) grit from GUYSONTM were chosen (Table 1). The grit was blasted using a 150 psi compressor in a Clarke ${ }^{\mathrm{TM}}$ blast cabinet (Figure 2). For each grit type he following two pressures and 
exposure times were used. In the rest of the text the samples are labelled as follows:

$\mathrm{NI}$ - no interface

I NG - tablet not modified before moulding

I_GB,20s@60psi - tablet glass bead blasted for $20 \mathrm{~s}$ at 60 psi

I_GB,60s@80psi - tablet glass bead blasted for $60 \mathrm{~s}$ at 80 psi

I FA,20s@60psi - tablet alumina blasted for $20 \mathrm{~s}$ at 60 psi

I_FA,60s@80psi - tablet alumina blasted for $60 \mathrm{~s}$ at $80 \mathrm{psi}$

\begin{tabular}{c|c|c|c}
\multicolumn{3}{c}{ TABLE 1 } \\
GRIT SPECIFICATION \\
\hline $\begin{array}{c}\text { Grit } \\
\text { name }\end{array}$ & $\begin{array}{c}\text { Grit } \\
\text { type }\end{array}$ & $\begin{array}{c}\text { Particle } \\
\text { shape }\end{array}$ & $\begin{array}{c}\text { Particle } \\
\text { size }[\boldsymbol{\mu m}]\end{array}$ \\
\hline Honite 13 & Soda-lime glass beads & Spherical & $106-212$ \\
Saftigrit & White fused alumina & $120-150$ \\
\hline
\end{tabular}

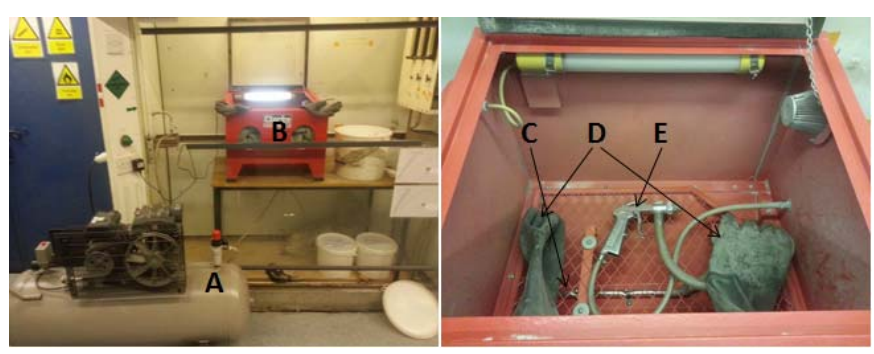

Figure 2. Grit-blasting equipment used. A: 150psi compressor, B: Clarke blast cabinet, C: Tube for grit intake, D: Protective gloves, E: Blast gun

\section{Interface characterization/evaluation}

Prior to their modification, the roughness of the epoxy tablets was characterized using a Carl Zeiss ${ }^{\mathrm{TM}}$ digital microscope controlled via a PC equipped with AxioVision software utilizing the Z-stack plug-in. This feature was programmed to acquire 10 slices (images) at different focal points. When this was done, all slices were superimposed on top of each other creating the surface's primary profile. The interface area of which the surface profile was acquired was $11.86 \mathrm{~mm}^{2}$ and the visual magnification used was $\mathrm{x} 100$.

A number of standards exist which aid towards the evaluation of a material surface's profile[8]-[10]. To determine the roughness profile, a Gaussian smoothing filter is passed through the primary profile based on a specific cutoff wavelength, lambda $(\lambda)$. The $\lambda$ value was chosen manually and it was done so by following the standard cut-off filter lengths recommended in the following standards [11]:

- ASTM: The evaluation length should contain a number of cutoff filter lengths.

- ISO: The evaluation length should contain one or more cutoff filter lengths.

- DIN: The evaluation length is five times the cutoff filter length.

All standards recommend five different cut-off lengths. Following Chapman Instruments technical note [11] which advised using two to five cut-off lengths for a "good statistical evaluation" and knowing our software limitation $(\lambda<2 \mathrm{~mm})$, three cut-off lengths used were $\lambda=80,250$ and $800 \mu \mathrm{m}$. The average roughness values recorded at each lambda were used to find the mean surface roughness for each tablet.

Grit-blasting decreased the mean surface roughness of the epoxy surfaces as seen in Figure 3.

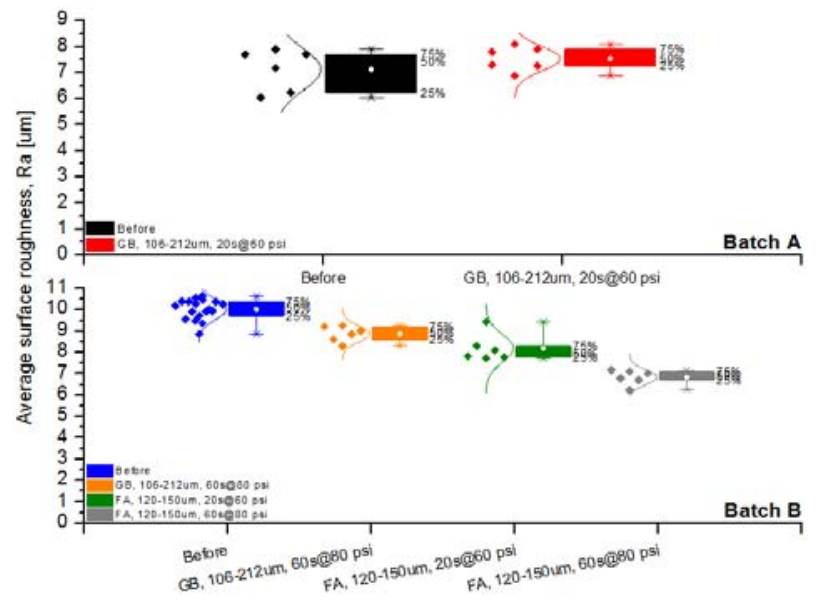

Figure 3. Mean surface roughness before/after grit-blasting

III. RESULTS AND DISCUSSION

Six sets of experimental data are presented in this section showing:

- electrical tree growth rate

- time taken for the tree to reach $1 \mathrm{~mm}, 1 \mathrm{~mm}+$ (penetrating the interface), $2 \mathrm{~mm}$, and breakdown

- relationship between time to breakdown and electrical tree width

- relationship between interface roughness before/after gritblasting and time to breakdown

- relationship between interface roughness before/after gritblasting and tree width

All data are plotted using scatter plots showing the individual data points, lines of best fit as well as data tables where appropriate.

\section{Electrical tree rate of growth}

This is the relationship between electrical tree length and the time elapsed from the high voltage application on the sample and until breakdown; illustrated in Figure 4. This figure only shows two typical curves for clarity.

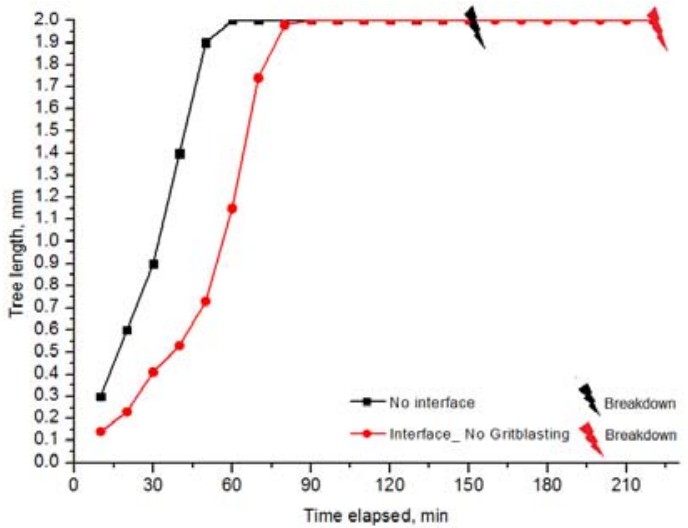

Figure 4. Typical tree growth an time to breakdown curves; shown for samples with and without an interface. 
It can be seen that when no interface is present, the electrical tree grows much faster and with a steeper slope when compared to the tree growth rate in an interface containing sample. This was always seen to be the case. There is also a difference in growth times and to breakdown and this is discussed in more detail in the following section.

\section{Tree growth and breakdown}

From inception and until breakdown, the electrical tree propagates through a number of important "checkpoints" that when observed closely, they might help towards the better understanding of the interface effect on the tree characteristics. The average times for the following have been recorded as seen in Table 3:

- $1 \mathrm{~mm}$ - This is also the "interface checkpoint" in samples containing interfaces

- $1 \mathrm{~mm}+$ - The time when the first electrical tree branch penetrated through the interface (did not apply in the samples containing no interface)

- $2 m m$ - The time when the first electrical tree branch reached the opposite electrode

- $B D$ - The time when breakdown occurred

TABLE 3

AVERAGE TIME TAKEN FOR TREE TO REACH "CHECKPOINTS"

\begin{tabular}{|c|c|c|c|c|}
\hline Sample type & $\begin{array}{c}\mathbf{1 m m} \\
{[\mathbf{m i n}]}\end{array}$ & $\begin{array}{c}\mathbf{1 m m +} \\
{[\mathbf{m i n}]}\end{array}$ & $\begin{array}{c}\mathbf{2 m m} \\
{[\mathbf{m i n}]}\end{array}$ & $\begin{array}{c}\text { BD } \\
{[\mathbf{m i n}]}\end{array}$ \\
\hline NI & 30.2 & -- & 50.4 & 89.8 \\
\hline I_NG & 51.33 & 61.7 & 74 & 128.5 \\
\hline I_GB,20s@60psi & 61.25 & 66.3 & 110 & 237 \\
\hline I_GB,60s@80psi & 48.4 & 51.6 & 95.2 & 208.4 \\
\hline I_FA,20s@60psi & 63.2 & 66.2 & 116.2 & 193.8 \\
\hline I_FA,60s@80psi & 55.25 & 60 & 108.5 & 253 \\
\hline
\end{tabular}

From the data presented in Table 3, it can be initially observed that there is a similar pattern developing for all the grit-blasted samples. This can be clearly seen in the analysis of Figure 5.

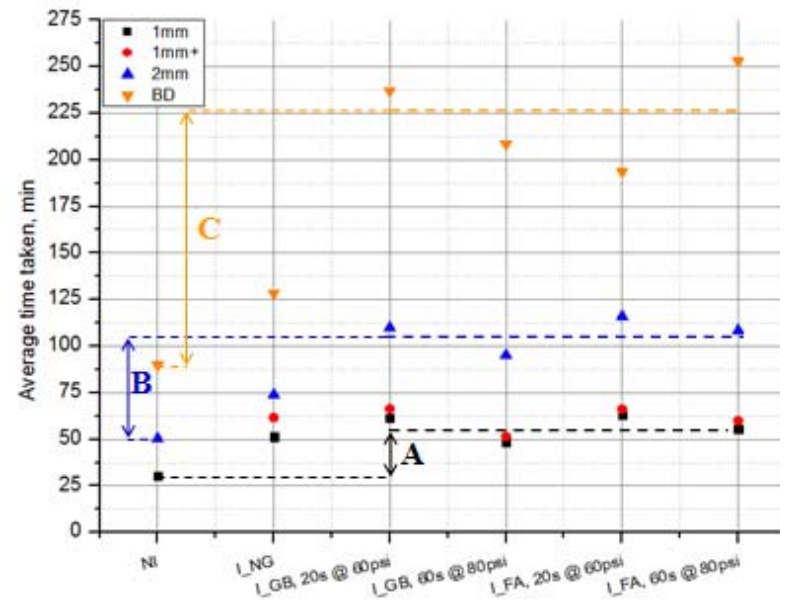

Figure 5. Electrical tree characteristic times for the various samples.

It can be observed that all the grit-blasted sample types have a very similar behavior as far as the time taken to reach $1 \mathrm{~mm}$ and $2 \mathrm{~mm}$ in length, characterised by the black and blue dashed lines respectively. A difference can be witnessed for the non-grit-blasted sample where although the time taken to reach $1 \mathrm{~mm}$ and $1 \mathrm{~mm}+$ is similar, the time taken to reach 2 $\mathrm{mm}$ is approximately 25 minutes less than the smallest gritblasted value. The time to breakdown was extended by 1 hour for the grit blasted samples also.

The biggest difference though is observed between the sample without any interface and those containing grit-blasted interfaces. To make observations easier, an averaging line was plotted between the data points of each grit-blasted type for $1 \mathrm{~mm}, 2 \mathrm{~mm}$ and BD. That time was compared against the corresponding times for the sample without an interface and it was divided in three segments, A, B, C as shown in Figure 5. A summary can be seen in Table 4 .

TABLE 4

\begin{tabular}{|l|c|c|}
\hline \multicolumn{3}{|c|}{ SIFFERENCE IN TIME REACHING 1MM, 2MM \& BD } \\
\hline A: $1 \mathrm{~mm}$ & $\begin{array}{c}\text { Difference between NI \& } \\
\text { Grit-blasted samples[min] }\end{array}$ & $\begin{array}{c}\text { Improvement } \\
\text { percentage [\%] }\end{array}$ \\
\hline B: $2 \mathrm{~mm}$ & 27 & 89 \\
\hline C: $\mathrm{BD}$ & 57 & 113 \\
\hline
\end{tabular}

Relationship between time to breakdown and electrical tree width

The correlation between the maximum electrical tree width prior to breakdown and breakdown time was investigated next as seen in Figures 6 a) \& b)
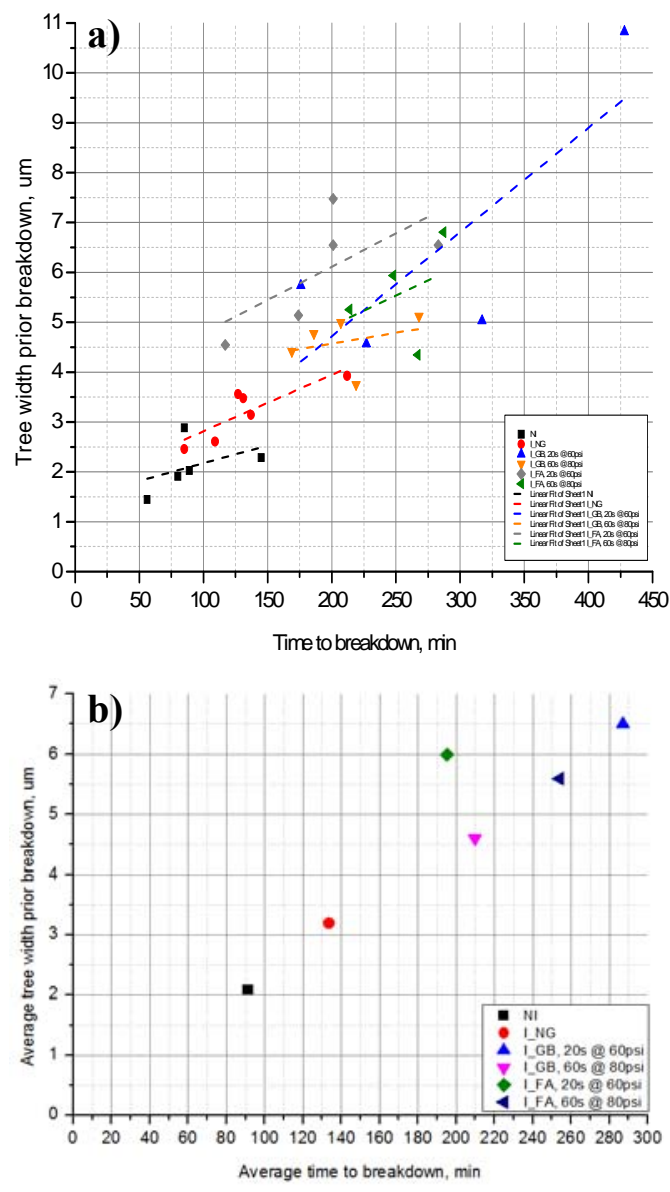

Figure 6. Relationship between a) time to breakdown and electrical tree width $b$ ) average time to breakdown and average electrical tree width for each sample type 
In Figure 6a), all individual sample data were plotted giving a fairly scattered appearance. For samples without any interface (NI) and samples with non-grit blasted interface (I_NG) it can be seen that the data points are grouped together mostly occupying breakdown times between $50-150$ minutes. On the other hand, the grit-blasted data points are more scattered occupying breakdown times between 150 430 minutes. Lines of best fit for each data series were plotted so that a view of the trend followed by each sample type as well as the interaction - if any- with other sample types could be seen.

In Figure $6 \mathrm{~b}$ ), the average breakdown values and tree width for each sample type were plotted. From the results presented it can be seen that there is a linear relationship between almost all sample types and this reveals a direct relation between the maximum electrical tree width prior to breakdown and time to failure.

Time to breakdown (Figure 7) and tree width (Figure 8) were plotted against the average surface roughness before and after grit-blasting. No clear correlation was evident between the surface roughness and tree growth or breakdown times.

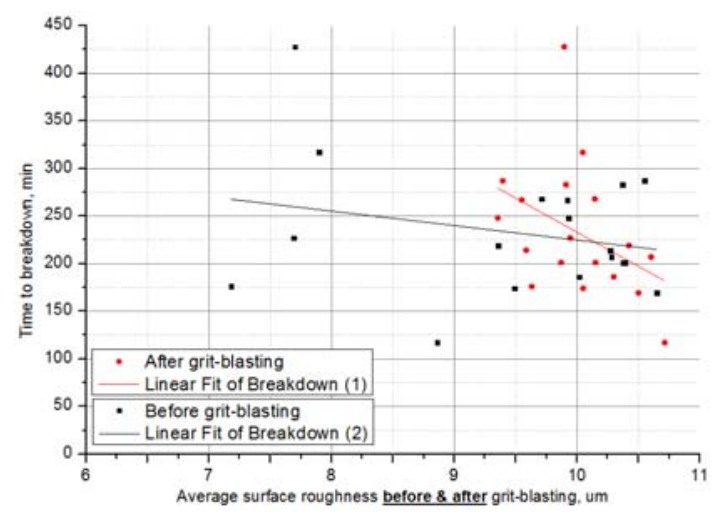

Figure 7. Relationship between time to breakdown and surface roughness before/after grit-blasting

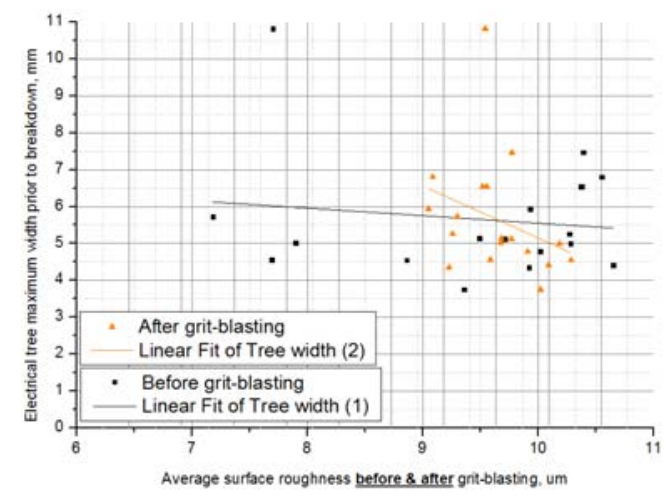

Figure 8. Relationship between tree width and surface roughness before/after grit-blasting

\section{DISCUSSION and CONCLUSIONS}

There was a significant increase in terms of the time taken for the electrical tree to reach $1 \mathrm{~mm}, 2 \mathrm{~mm}$ and BD. The improvement percentage starts from $89 \%$ for the time taken to reach $1 \mathrm{~mm}$ and increases by approximately $30 \%$ from one checkpoint to the other.

From the results presented it can be seen that there is an inverse linear relationship between the maximum electrical tree width prior to breakdown and time to failure. It can be said that the average time to breakdown increases as average tree width increases as well. The presence of the interface appears to lead to a wider tree growing, which both slows the tree growth and extends time to breakdown. It is suggested that the wider tree is due to space charge accumulation at the interface modifying the electrical field, and this in turn reduces the field enhancement due to the tree itself, further extending the epoxy lifetime.

The perpendicular interface slowed tree growth and extended time to failure. Grit blasting of the interface before fabrication improved performance further, but no evidence was found that this was due to changes in surface roughness.

\section{ACKNOWLEDGMENT}

This work is part of the EPSRC Supergen HubNet Project under grant number EP/I013636/1. http://www.hubnet.org.uk/

\section{REFERENCES}

[1] M. Pattouras, A. Tzimas, and S. M. Rowland, "The effect of material interfaces on electrical tree growth and breakdown time of epoxy resin," in Conference on Electrical Insulation and Dielectric Phenomena, 2013, pp. 1-4.

[2] R. Vogelsang and R. Brutsch, "Electrical tree propagation along barrier-interfaces in epoxy resin," in Conference on Electrical Insulation and Dielectric Phenomena, 2002, pp. 946-950.

[3] K. Theodosiou, "The Role of A Dielectric Barrier in Electrical Trees Initiation in Solid Dielectrics," J. Electr. Eng., vol. 59, no. 5, pp. 248253, 2008.

[4] D. Suwarno, "A Model and Computer Simulation of Partial Discharges in High Voltage Liquid Insulation," in Asia International Conference on Mathematical/Analytical Modelling and Computer Simulation, 2010, pp. 444-449.

[5] R. Bozzo, G. Coletti, and A. Hagi, "Pre-breakdown phenomena in XLPE under highly divergent field conditions," in ConfereConduction and Breakdown in Solid Dielectrics, 1992, pp. 545-550.

[6] R. Bozzo, "Evaluation of insulating materials on the basis of electrical treeing and breakdown tests," in Conference on Conduction and Breakdown in Solid Dielectrics, 1992, pp. 539-544.

[7] S. Bahadoorsingh and S. M. Rowland, "Investigating the influence of the lubricant coating on hypodermic needles on electrical tree characteristics in epoxy resin," IEEE Trans. Dielectr. Electr. Insul., vol. 17, no. 3, pp. 701-708, Jun. 2010.

[8] American Society of Mechanical Engineers (ASME), "Surface Texture (Surface Roughness, Waviness, and Lay)” B46.1, 2009.

[9] International Organization for Standardization (ISO), "Geometrical Product Specifications (GPS) -- Surface texture: Profile method -Rules and procedures for the assessment of surface texture", ISO 4288:1996, 2013.

[10] International Organization for Standardization (ISO), "Geometrical product specifications (GPS) -- Filtration -- Part 31: Robust profile filters: Gaussian regression filters", ISO/TS 16610-31:2010, 2014.

[11] Chapman Instruments, "Spatial Filtering of Surface Profile Data", Chapman Technical Note-TG-1, 2009. 